\title{
Linguistic barriers in diabetes care
}

\author{
G. Reach
}

Received: 16 April 2009/Accepted: 30 April 2009/Published online: 13 June 2009

(C) Springer-Verlag 2009

\begin{abstract}
For a message to be conveyed successfully, both the words (translation step) and the meaning (interpretation step) of what is said need to be understood. This holds true even when the patient and healthcare provider speak the same language, in that the message can be lost if the patient is unable to put it into context. Linguistic barriers can pose major problems. Patient education needs to avoid jargon, and when introducing a new concept to the patient, the healthcare provider needs to check that it is understood.
\end{abstract}

Keywords Chinese Room argument · Language ·

Linguistic barriers $\cdot$ Literacy $\cdot$ Numeracy $\cdot$ Patient education

The aim of this paper is to investigate what is meant by a 'linguistic barrier' between the patient and healthcare provider. This concept will be illustrated by examples taken from the setting of diabetes care, but it applies to any patient-healthcare provider relationship, whatever the medical context.

\section{Clinical vignette: the strange case of Mrs Li}

Consultations with Mrs Li are difficult, mainly because she attends them either alone or accompanied by someone who,

\footnotetext{
G. Reach $(\bowtie)$

Service d'Endocrinologie Diabétologie Maladies Métaboliques, Hôpital Avicenne APHP,

125 route de Stalingrad,

93000 Bobigny, France

e-mail: gerard.reach@avc.aphp.fr

G. Reach

Université Paris 13,

CRNH-IdF, EA 3412,

Bobigny, France
}

like her, only speaks Chinese [1]. All I can do, to attempt to explain her repeatedly high $\mathrm{HbA}_{1 \mathrm{c}}$ levels, is to look at her log-book and try to understand the documented insulin doses and the blood glucose concentrations. I recently admitted her to hospital. First, I verified that Mrs Li had the technical expertise to be able to determine blood glucose levels and inject insulin correctly. I then gave her to understand that I needed an interpreter. A Chinese neighbour who was fluent in French was present the following day. I first checked the basics of adapting insulin doses with $\mathrm{Mrs} \mathrm{Li}$ and began to ask her questions through the interpreter. No answer. I therefore asked the interpreter if he, himself, had understood the meaning of the questions. He gave an affirmative response. I then asked Mrs Li to tell me what she thought the insulin was for. No answer. I realised that she knew nothing about it and that the treatment made absolutely no sense to her.

\section{An interpretation of linguistic barriers: the Chinese Room argument}

Imagine a man in a closed room fitted with a glass panel. From time to time someone outside the room holds up a question written in Chinese characters. The man inside the room has no knowledge of Chinese, but responds by checking the symbols against a set of written instructions. These tell him the correct response, also written in Chinese, which he shows in reply. All this is meaningless from his point of view, but Chinese observers outside the room will conclude that he understands Chinese.

This famous metaphor, known as the Chinese Room argument, was proposed in 1980 by the American philosopher John R. Searle [2]. He used it as an argument against the possibility of true artificial intelligence: while suitably 
programmed computers may appear to converse in natural language, they are not capable of understanding language, even in principle. Indeed, they manipulate symbol strings, but have no understanding of meaning. I recently proposed to apply this metaphor to the case of $\mathrm{Mrs} \mathrm{Li}$, described above [1]. Indeed, we doctors had observed that she measured blood glucose and injected insulin correctly, and even seemed to apply adjustment rules; as the Chinese people outside the Chinese Room who thought that the man inside the room understood Chinese, we believed that Mrs Li understood the meaning of diabetes therapy. In Mrs Li's case, we, the doctors, played the role of the Chinese people in Searle's argument.

Suppose now that I use an interpreter who would speak French (with me) and then Chinese (with Mrs Li). Obviously, we may have resolved the first part of the problem, that concerning the words, but not the second part, that involving the meaning. Indeed, the interpreter may not understand what I say, although both of us speak the same language (French). Next, Mrs Li may not understand what the interpreter tells her in their common language (Chinese).

Now replace the Mrs Li of our clinical vignette with a patient speaking your language, measuring blood glucose and injecting insulin. The preceding paragraph suggests that this does not prove that he/she understands the meaning of his/her treatment. Why?

\section{Saussure's distinction between langue and parole}

In his Cours de Linguistique Générale (1906-1911), the Swiss linguist Ferdinand de Saussure proposed that language has two components, 'langue' and 'parole' [3]. Langue is the whole system of language that precedes speech and makes speech possible. Learning a language, we master the system of grammar, spelling, syntax and punctuation; these are all elements of langue. Parole is the concrete use of the language, the actual utterances. It is an external manifestation of langue.

In a recent Editorial, Gregg and Saha [4] proposed to apply this distinction to the issue of communicative competence in healthcare. I wish to emphasise that this distinction is relevant even in the case of language concordance. First, the patient may not understand the words, because the physician uses another langue, a medical jargon, and second, he/she may not understand the parole, i.e. the meaning of what is said, even if he/she understands the words. Physicians frequently use jargon. They are often of the opinion that they invest a lot of time, money and effort to learn their very exact vocabulary, and may therefore be reluctant to simplify their terminology when speaking to a patient [5]. For instance, in the past there was debate between scholars to decide whether one should use the word 'glycosylated' or 'glycated' when referring to $\mathrm{HbA}_{1 \mathrm{c}}$, forgetting that the patient might not understand either term and might prefer to discuss 'sugared haemoglobin'!

\section{Understanding the parole: health literacy and numeracy, ethnicity and culture}

Health literacy is defined as 'the degree to which individuals have the capacity to obtain, process and understand basic health information and services needed to make appropriate health decisions' [6]. Patients classified as having a low health literacy less frequently have a basic knowledge of diabetes care [7] and more frequently have a high $\mathrm{HbA}_{1 \mathrm{c}}$ level and retinopathy [8]. Health numeracy refers to 'the degree to which individuals have the capacity to access, process, interpret, communicate, and act on numerical, quantitative, graphical, biostatistical, and probabilistic health information needed to make effective health decisions' [9]. Patients with a low level of numeracy have a lower ability to perform a number of tasks required for their treatment, such as carbohydrate counting, identification of self-monitored blood glucose values within the target range and adjustment of insulin doses [10].

Finally, the message can be lost even after an appropriate translation if its content does not match the psychology of the patient, with all its influences-familial, ethnic, cultural, historical, etc.

\section{Conclusion}

As illustrated by the Chinese Room metaphor, successful patient education cannot consist of teaching somebody the equivalent of responding to a pictogram with another pictogram. Most medical visits involve the introduction of a novel concept to the patient, and it is important that the healthcare provider explains the concept and checks that this has been understood, and, if necessary, clarifies and tailors the information to the patient [11].

Healthcare providers need to make efforts to communicate effectively when treating language-discordant patients and, indeed, when seeing language-concordant patients. This is of paramount importance, since for any relationship between a patient and healthcare provider, conversation is the means to put an end to what Katz called 'the silent world of doctor and patient' [12]. However, conversation is possible if, and only if, linguistic barriers are, at least in large part, overcome.

Acknowledgements This paper was presented at the 12th Rencontres Franco-Américaines de Bobigny, Bobigny, France, 26 March 2009. The clinical vignette was published as a filler ('a memorable patient') in the $B M J$ [4]. 
Duality of interest The author declares that there is no duality of interest associated with this manuscript.

\section{References}

1. Reach G (2008) A memorable patient: the "Chinese room" argument and patient education. BMJ 336:365

2. Searle J (1980) Minds, brains, and programs. Behav Brain Sci 3:417-424

3. De Saussure F (1916) Bally C, Sechehaye A (eds) Cours de linguistique générale. Payot, Paris

4. Gregg J, Saha S (2007) Communicative competence: a framework for understanding language barriers in health care. J Gen Intern Med 22(Suppl 2):368-370

5. Root MJ (1987) Communication barriers between older women and physicians. Public Health Rep 102:152-155

6. Selden CR, Zorn M, Ratzan SC, Parker RM (2000) National Library of Medicine Current Bibliographies in Medicine: Health Literacy. NLM Pub. No. CBM 2000-1. National Institutes of
Health, US Department of Health and Human Services, Bethesda. Available from www.nlm.nih.gov/archive//20061214/pubs/cbm/ hliteracy.html. Accessed 5 May 2009

7. Williams MV, Baker DW, Parker RM, Nurss JR (1998) Relationship of functional health literacy to patients' knowledge of their chronic disease: a study of patients with hypertension and diabetes. Arch Intern Med 158:166-172

8. Schillinger D, Grumbach K, Piette J, Wang F, Osmond D, Daher C et al (2002) Association of health literacy with diabetes outcome. JAMA 288:475-482

9. Golbeck AL, Ahlers-Schmidt CR, Paschal AM, Dismuke SE (2005) A definition and operational framework for health numeracy. Am J Prev Med 29:375-376

10. Cavanaugh K, Huizinga MM, Wallston KA et al (2008) Association of numeracy and diabetes control. Ann Intern Med 148:737-746

11. Schillinger D, Piette J, Grumbach K et al (2003) Closing the loop: physician communication with diabetic patients who have low health literacy. Arch Intern Med 163:83-90

12. Katz J (1984) The silent world of doctor and patient. John Hopkins University Press, Baltimore 